\title{
Hollow Viscus Injuries Due To Trauma
}

\author{
Ajmeera Ranga ${ }^{\circledR}$, Kongara Rajesh ${ }^{\circledR}$ \\ Assistant Professor, Department of Surgery, Gandhi Medical College, Secunderabad, Telangana, India.
}

\section{Abstract}

Background: Hollow viscus injuries can be due to traffic accidents, fall from the height, and fall of heavy objects leading to trauma. Abdominal trauma is the most common with Injuries pertaining to Gastro-Intestinal tract from the cardiac end of the esophagus to the anus, gall bladder, and biliary tract and lower genitourinary tract. The aim of the study is to study the modes of trauma, clinical features of hollow viscus injuries, and the diagnosis and management of hollow viscus injuries. Subjects and Methods: This was a hospital-based cross-sectional study. conducted over a period of one year from June 2018 - May 2019. at Department of General Surgery on 90 patients with hollow viscus injury. After initial resuscitation of the trauma victims, a careful history was taken to document any associated medical problem. The collected data was analyzed with respect to the presentation by the patient's age and sex incidence, etiologies, pathological features, morbidity, and mortality associated with causation and management. The ultrasound and CT- Scan were done to assess the injury and plan accordingly before taking up for the surgery. Results: The majority of the patients belonged to the age group of $21-30$ years and the least pertaining to the age group of $41-50$ years of age group. The Incidence in Males is much more than females. The males were $74 \%$ and females were $26 \%$. The most common causative agent of hollow viscous injury was a Road traffic accident with 59\%. Majority of the patients who were admitted more than 24 hours after the injury, the mortality rate was much higher compared to the patients who were admitted in less than 24 hours of the trauma. Conclusion: HVI is a dangerous condition. High mortality rates represent the seriousness of HVI and related injuries. Patients of HVI should be carefully monitored for associated injuries and complications.

Keywords: Hollow viscous injury, blunt injury abdomen, Ultra Sonography

Corresponding Author: Ajmeera Ranga, Assistant Professor, Department of Surgery, Gandhi Medical College, Secunderabad, Telangana, India. E-mail: drrangajamera@gmail.com

Received: 7 May 2020

Revised: 11 June 2020

Accepted: 21 June 2020

Published: 5 July 2020

\section{Introduction}

Traumatic injuries are the leading cause of death in the world and it accounts for substantial morbidity in the population. Hollow viscus injury (HVI) following blunt abdominal trauma is an infrequent diagnosis that is usually inflicted by forceful mechanisms that cause serious associated injuries. ${ }^{[1]}$ The rate of hollow abdominal injury wounds varies from $4 \%$ to $15 \%$. ${ }^{2]}$ Patients of abdominal trauma often suffer from HVI. Such condition is not frequent in blunt abdominal trauma, because the injury should be severe. Solid-organ damage and consequent hemodynamic dysfunction have a higher priority for the management of blunt abdominal trauma, however, HVI is typically not assumed unless the clinical picture becomes highly suggestive. Delays in the diagnosis and treatment of hollow viscous injury are well known, leading to early peritonitis, hemodynamic instability, increased mortality, and morbidity. The reduction in the penetrating level of abdominal trauma and the increase in the rate of blunt abdominal trauma has resulted in hollow viscus injuries being increased.
Effective Diagnosis and treatment, therefore, remain the significant management component.

Managing blunt abdominal trauma triggering hollow viscus injury is a herculean task for both anesthesiologists and surgeons. The diagnosis of hollow viscus injury is delayed because the most apparent stable visceral injuries that frequently accompany it are managed non-operatively, and imagery studies (CT scans in particular) may not show them soon after the injury.

Early surgical intervention is of paramount importance in case of hollow viscus injury, in contrast to the non-operative management of total muscular visceral injury. Delayed diagnosis and consequently treatment increase morbidity and mortality. ${ }^{[3,4]}$

\section{Subjects and Methods}

Place of Study: Department of General Surgery

Type of Study: Hospital-based cross-sectional study 
Sample Collection: Sample size: 90 Patients with Hollow viscus injury

Sampling Methods: Consecutive sampling

\section{Inclusion Criteria}

Patients above the age of 11 years with blunt injury due to Road Traffic Accidents, Train Traffic Accidents or Fall from height or Fall of heavy objects were included in our study.

\section{Exclusion Criteria}

Patients below the age of 11 years, Genitourinary, biliary, \& pancreatic injury, Injuries caused by blast injuries \& gunshot injuries were excluded from our study.

\section{Statistical Analysis}

Data were presented in the form of statistical tables and charts. SPSS software version 20 was used for statistical analysis.

\section{Ethical Approval}

Approval was taken from the Institutional Ethics Committee prior to the commencement of the study.

Patients coming with blunt injury due to Road Traffic Accidents, Train Traffic Accidents, or Fall from height or Fall of heavy objects were admitted to the department of general surgery. Data collected with a detailed background, clinical investigations and radiological, serological, histopathological, and surgical results of those patients who were admitted. Postoperative follow up was done to note for complications. After the initial resuscitation of the trauma victims, a careful history was taken to document any associated medical problem. The collected data was analyzed with respect to the presentation by the patient's age and sex incidence, etiologies, pathological features, morbidity, and mortality associated with causation and management. The ultrasound and CT- Scan were done to assess the injury and plan accordingly before taking up for the surgery.

\section{Results}

The majority of the patients belonged to the age group of 21 -30 years and the least pertaining to the age group of $41-$ 50 years of age group. The Incidence in Males is much more than females. The males were $74 \%$ and females were $26 \%$. The most common causative agent of hollow viscous injury was Road traffic accident with 59\%.

The significant injury associated in trauma was Polytrauma with $26 \%$ followed by orthopedic injuries constituting $24 \%$, Head injuries in $15 \%$ and the least being the thoracic injuries seen in $8 \%$ of the patients.

The majority of the patients around $67 \%$ were operated within 12 hours of the injury of the surgery. Only $1 \%$ of the patients were produced more than $48 \mathrm{hrs}$ after the damage due to conservative management as the risk was more complicated.
Table 1: Distribution of the patients with regards to age, gender and Causative agent.

\begin{tabular}{lll}
\hline Age group (yrs) & No. Of patients & Percentage (\%) \\
$11-20$ & 21 & 21 \\
$21-30$ & 34 & 34 \\
$31-40$ & 26 & 26 \\
$41-50$ & 8 & 8 \\
$>50$ & 9 & 9 \\
Gender & & $74 \%$ \\
Male & 74 & $26 \%$ \\
Female & 26 & \\
Causative agent & & 59 \\
Road traffic acci- & 59 & 8 \\
dent & & 24 \\
$\begin{array}{l}\text { Train traffic acci- } \\
\text { dent }\end{array}$ & 8 & 9 \\
\hline $\begin{array}{l}\text { Fall from height } \\
\text { Stab Injury }\end{array}$ & 24 & 9
\end{tabular}

\begin{tabular}{lll}
\hline \multicolumn{2}{l}{ Table 2: Associated injuries with trauma } \\
\hline Injuries & No. of Pts & Percentage \\
Head & 15 & $15 \%$ \\
Thoracic & 8 & $8 \%$ \\
Orthopedic & 24 & $24 \%$ \\
Polytrauma & 26 & $26 \%$ \\
\hline
\end{tabular}

\begin{tabular}{lll}
\hline \multicolumn{2}{l}{ Table 3: Latent Time, Time between injury and surgery } \\
\hline Hours & No. Of cases & Percentage \\
\hline $0-12$ & 67 & $67 \%$ \\
$12-24$ & 30 & $30 \%$ \\
$24-48$ & 2 & $2 \%$ \\
$>48$ & 1 & $1 \%$ \\
\hline
\end{tabular}

Table 4: Mortality of patients based on reporting to the hospital after injury

\begin{tabular}{lll}
\hline Mortality & No. of patients & Percentage \\
$\begin{array}{l}\text { Presentation }<24 \\
\text { hrs }\end{array}$ & 6 & $6 \%$ \\
$\begin{array}{l}\text { Presentation }>24 \\
\text { hrs }\end{array}$ & 12 & $12 \%$ \\
\hline
\end{tabular}


Majority of the patients who were admitted more than 24 hours after the injury the mortality rate was much higher compared to the patients who were admitted in less than 24 hours of the trauma.

\section{Discussion}

Hollow Viscus Injuries are common in India following blunt trauma due to road and rail accidents and multiple stab injuries due to south Indian movies inspired scenes that portray extreme heinous crimes which goons are using to take out their threats or enemies. Morbidity and mortality are high and adverse CT-Scan are not adequate to exclude these accidents in some clinical scenarios. These incidents are often not suspected and are challenging to diagnose.

The majority of the patients were teenagers belonging to the young and productive age group of $21-30$ years and the least pertaining to the age group of $41-50$ years of age group. ${ }^{[5-7]}$ In Davis et al study the majority of patients belonged to 21-30 years age group. ${ }^{[5]}$

The Incidence in Males is much more than females. The males were $74 \%$ and females were $26 \%$. In Davis et al study the males were $70 \%$ and females were $30 \%$ which were similar to our research. As in India, males are the family's sole breadearners and, most of the Time involved in outdoor workrelated activities.

The most common causative agent of hollow viscous injury was Road traffic accident (RTA) with 59\%. ${ }^{[8]}$ Davis et al \& Khanna et al study also showed the most common causative agent of hollow viscus injury was RTA with $70 \%$ and $57 \%$ respectively. ${ }^{[5,6]}$ This is because of the rapid technological growth in all domains, including in the automotive industry, where speed rather than health has been the emphasis.

The significant injury associated with trauma was Polytrauma with $26 \%$ followed by orthopedic injuries constituting $24 \%$, Head injuries in $15 \%$ and the least being the thoracic injuries seen in $8 \%$ of the patients. The Majority of the patients around were admitted within 24 hours of the damage. ${ }^{[7-9]}$ The majority, about $67 \%$ were operated within 12 hours of the injury of the surgery. Only $1 \%$ of the patients were produced more than $48 \mathrm{hrs}$ after the damage due to conservative management as the risk was more complicated. Majority of the patients who were admitted more than 24 hours after the injury the mortality rate was much higher compared to the patients who were admitted in less than 24 hours of the trauma. The most common cause of mortality was septicemia. ${ }^{[10]}$

\section{Conclusion}

Hollow Viscus Injuries are common in trauma patients, many predictive factors for morbidity and mortality have been established and treatment delays have been described as a clear indicator of morbidity that significantly influences the postoperative path.

\section{References}

1. Fakhry SM, Brownstein M, Watts DD, Baker CC, Oller D. Relatively Short Diagnostic Delays ( $<8$ Hours) Produce Morbidity and Mortality in Blunt Small Bowel Injury: An Analysis of Time to Operative Intervention in 198 Patients from a Multicenter Experience. J Trauma. 2000;48(3):408415. Available from: https://dx.doi.org/10.1097/00005373200003000-00007. doi:10.1097/00005373-200003000-00007.

2. Bruscagin V, Coimbra R, Rasslan S, Abrantes WL, Souza HP, Neto $\mathrm{G}$, et al. Blunt gastric injury. A multicentre experience. Injury. 2001;32(10):761-764. Available from: https://dx. doi.org/10.1016/s0020-1383(01)00081-x. doi:10.1016/s00201383(01)00081-x.

3. Fakhry SM, Brownstein M, Watts DD, Baker CC, Oller D. Relatively Short Diagnostic Delays $(<8$ Hours) Produce Morbidity and Mortality in Blunt Small Bowel Injury: An Analysis of Time to Operative Intervention in 198 Patients from a Multicenter Experience. J Trauma. 2000;48(3):408 415. Available from: https://dx.doi.org/10.1097/00005373200003000-00007. doi:10.1097/00005373-200003000-00007.

4. Malinoski DJ, Patel MS, Yakar DO, Green D, Qureshi F, Inaba K, et al. A Diagnostic Delay of 5 Hours Increases the Risk of Death After Blunt Hollow Viscus Injury. J Trauma. 2010;69(1):84-87. Available from: https://dx.doi.org/10.1097/ ta.0b013e3181db37f5. doi:10.1097/ta.0b013e3181db37f5.

5. Davis JJ, Cohn I, Nance FC. Diagnosis and Management of Blunt Abdominal Trauma. Ann Surg. 1976;183(6):672678. Available from: https://dx.doi.org/10.1097/00000658197606000-00009. doi:10.1097/00000658-197606000-00009.

6. Khanna R, Khanna S, Singh P, Puneet, Khanna AK. Spectrum of blunt abdominal trauma in Varanasi. Quarterly J Surg Sciences. 1999;(1\&2):25-28.

7. Shrihari V, Jayran J, Sabira S. Clinical study of blunt trauma abdomen. Ind J Res. 2015;4(1):123-129.

8. Tripathi MD, Srivastava RD, Nagar AM, Pratap VK, Dwivedi SC. Blunt abdominal trauma with particular reference to early detection of physical injuries. Indian J Surg. 1991;53(5):17984.

9. Sharma A, Hitendra. Study of blunt abdominal cases and management. Int J Sci Res. 2015;4(10).

10. Bajiya P, Jain S, Meena L. Gastrointestinal perforation following blunt trauma abdomen: a study of 78 cases. Int J Med Sci Public Health. 2016;5(6):12251225. Available from: https://dx.doi.org/10.5455/ijmsph.2016. 10032016379. doi:10.5455/ijmsph.2016.10032016379. 
Copyright: (C) the author(s), 2020. It is an open-access article distributed under the terms of the Creative Commons Attribution License (CC BY 4.0), which permits authors to retain ownership of the copyright for their content, and allow anyone to download, reuse, reprint, modify, distribute and/or copy the content as long as the original authors and source are cited.

How to cite this article: Ranga A, Rajesh K. Hollow Viscus Injuries Due To Trauma. Acad. J Surg. 2020;3(1):163-166.

DOI: dx.doi.org/10.47008/ajs/2020.3.1.35

Source of Support: Nil, Conflict of Interest: None declared. 